\title{
EXPERIMENTOS DO ÊXODO: JULIO LE PARC E O GRAV
}

\author{
EXODUS EXPERIMENTS: JULIO LE PARC AND GRAV
}

\author{
Leandro Candido de Souza* \\ lecanza@yahoo.com
}

RESUMO: Este artigo tem como objetivo analisar os primeiros anos da produção artística de Julio Le Parc (1928-) em solo francês, abarcando as obras elaboradas entre o início de sua residência (1958) e a consolidação política de suas atividades, a partir da exposição Amérique Latine Non Officielle (1970). Desse modo, espera-se demonstrar como a coexistência entre cinetismo, experimentação perceptiva e interação lúdica no GRAV (Groupe de Recherche d'Art Visuel, 1960-1968), não só preparou o terreno para a consagração internacional do artista (alcançada com o prêmio na Bienal de Veneza em 1966), como criou as condições para um exercício de funcionalização política da arte como instrumento de denúncia (em solo europeu) da luta dos povos oprimidos, especialmente os latino-americanos.

PALAVRAS CHAVE: Julio Le Parc, Vanguardas latino-americanas, Arte política.

ABSTRACT: This article is intended to analyze the first years of artistic production by Julio Le Parc (1928-) in French, covering works created from the start of his residence (1958) and his activities' political consolidation as of the exhibition Amérique Latine Non Officielle (1970). Hence, it is expected to demonstrate how the coexistence between kinetics, perceptive experimentation and playful interaction in the GRAV (Groupe de Recherche d'Art Visuel, 1960-1968), not only prepared the ground for the artist's international acknowledgement (obtained by means of the Venice Biennial award in 1966), but also created conditions for an exercise of political functionalization of art as a complaint instrument (in European soil) of the oppressed peoples resistance, especially the Latin American.

KEYWORDS: Julio Le Parc, Latin American vanguards, Political art.

\section{Pós-modernidade: deslocamento e expropriação ${ }^{1}$}

Julio Le Parc não chegou a Paris na condição de exilado, integrou a primeira onda migratória de latino-americanos que ainda não decorria diretamente da perseguição política. Suas motivações estavam mais ligadas ao desenvolvimento profissional que à clandestinidade, o que só amplia a problemática envolvendo o conceito de diáspora. Desde

\footnotetext{
* Graduado em ciências sociais pelo Centro Universitário Fundação Santo André (CUFSA), mestre pela ECA-USP e doutor em história pela PUC-SP.

${ }^{1}$ Este artigo sintetiza as consultas que realizei nos arquivos do Instituto Torcuato Di Tella (Fondo del Centro de Artes Visuales de la Universidad Torcuato Di Tella), na biblioteca do Museo Nacional de Bellas Artes e nos arquivos do Museo de Arte Moderna de Buenos Aires, entre os meses de abril e junho de 2015. O estágio só foi possível graças ao financiamento regular da FAPESP (pós-doutorado) e às supervisões dos professores Dr. Carlos Eduardo Jordão Machado (UNESP, Assis) e Dr. Miguel Vedda (FCL-UBA/Cátedra Libre Teoría Crítica y Marxismo Occidental). Durante esse período contribuíram e facilitaram esse trabalho: as equipes da Biblioteca da Universidad Torcuato Di Tella (especialmente Verónica Cánepa, Responsable de Archivos de Biblioteca), da Biblioteca Raquel Edelman del Museo Nacional de Bellas Artes (sobretudo Carolina Moreno, Bibliotecaria Referencista) e da Biblioteca y Centro de Documentación del Museo de Arte Moderno de Buenos Aires.
} 
o início de sua formação, por não ter conseguido se inserir no então exíguo mercado artístico argentino, Le Parc teve que conciliar seus estudos na Escuela de Bellas Artes Prilidiano Pueyrredón com trabalhos diurnos, até partir para a França com sua bolsa de oito meses fornecida pela embaixada francesa. E mesmo depois de mais oito meses, após a renovação do financiamento, sua tentativa parisiense não obteve o sucesso por ele esperado.

E se Le Parc não deve ser, ao menos até então, considerado um exilado, tampouco pode ser confundido com os "viajantes intelectuais" do século XIX. Luís Felipe Noé (1933-), argentino de trajetória semelhante à de Le Parc, pois esteve no exterior primeiro como estudante e depois como exilado, abordou de forma bastante adequada essa questão em seu artigo "Responsabilidad del artista que se va de América Latina y del que se queda", de 1966. Segundo Noé, a diferença residia na consciência e responsabilidade de resistência à crescente de penetração cultural que lhes empurrava para fora de seus países.

Na trajetória de Le Parc, esse compromisso estava associado aos esforços franceses de disputa pela hegemonia cultural global. Um movimento combinado que se consolidou, a partir de 1959, com a criação o Ministério da Cultura francês - por André Malraux (19011976) - e que, depois, sustentou uma rede de fomento ao intercâmbio internacional que também envolvia o Ministério de Relações Exteriores e o Premio Braque oferecido pela embaixada francesa em Buenos Aires entre 1963 e $1969 .^{2}$

A promessa, por parte principalmente de Estados Unidos e França, de transformar Buenos Aires em um novo centro de circulação do mercado de arte avançada, justamente por ainda não passar de uma promessa, foi o que obrigou Le Parc, como tantos outros artistas, a sair do país. A migração se tornava uma condição da profissionalização ou simplesmente sobrevivência para os não contemplados pelo mercado local que passava por um processo de financeirização multinacional. É nessa zona intermediária, entre a viagem cultural e o exílio em massa, que encontramos Julio Le Parc, indicando que havia algo mais

\footnotetext{
${ }^{2}$ A crescente dos números fala por si: em 1956 foram concedidos 1.500 financiamentos, em 1959 foram 2.400 e em 1969 o número chegou a 5.900. Além de Le Parc, alguns dos argentinos beneficiados com tais ajudas foram Alicia Penalba, Damián Bayón, Sergio de Castro, Alberto Greco, Graciela Martínez, Nicolás García Uriburu, María Simón, Armando Durante, Delia Cancela, Pablo Mesejean, Juan Carlos Stoppani e Gabriel Messil (PLANTE, 2013b, p. 38-54). Mais a diante no livro, Plante transcreve o trecho da carta em que Uriburu noticia a Damián Bayón o recebimento do prêmio Braque: "A bolsa é uma merda de 480NF" (PLANTE, 2013b, p. 100).
} 
que agiotagem nessa intromissão progressiva de capitais financeiros ocorrida na América Latina desde o segundo pós-guerra.

Estimativas conservadoras falam, no caso argentino, em mais de 120 mil exilados na década de 1960 e menos de 250 mil no decênio seguinte. Ou seja, mesmo que o número tenha dobrado em dez anos, apenas agravou-se um processo posto em marcha desde antes. Basta para isso lembrarmos que o relato de Rodolfo Walsh (1927-1977) em Operación Masacre é de 1956, o que revela a existência, desde então, de fuzilamentos clandestinos por parte de agentes do Estado. Marina Franco, em seu artigo "Testemoniar e informar: exilados argentinos en París (1976-1983)" assinala que "as estimativas mais realistas situam as cifras totais de saída em umas 500.000 pessoas" (FRANCO, 2004, §11). Já Osvaldo Coggiola e Edgardo Bilsky afirmam, em sua História do movimento operário argentino, que "mais de um milhão [de pessoas] optou pelo exílio, fugindo das diversas formas de repressão e da miséria. O Centro de Estudos Legais e Sociais calculou, em 1983, em 2,5 milhões o número de argentinos vivendo no exterior (10\% da população de 1976)" (COGGIOLA, BILSKY, 1999, p. 151).

Indiscutível é que foram estes primeiros imigrantes que deram início à construção institucional que amparou os refugiados da década seguinte. Na Argentina, nesse período e depois, esse fenômeno recebeu uma interpretação claramente nacionalista. É a crítica a essa chave interpretativa que magnetiza a reflexão de Noé, obrigando-o a ler o prêmio concedido a Le Parc na Bienal de Veneza, em 1966, não como reconhecimento da arte argentina, mas, antes, da Escola de Paris: a arte parisiense pós-cubista a que um Le Parc cinético estava associado no imaginário crítico francês. $\mathrm{O}$ cinetismo era a arte que a França procurava para fazer frente à pintura norte-americana representada metonimicamente pelo art dealer Leo Castelli (1907-1999). O próprio Le Parc, em sua visão retrospectiva é bastante claro a esse respeito. Aos 86 anos o artista registrou na matéria "Pequeño Le Parc ilustrado" da revista Art Democracy:

Eu não me auto-intitulo um artista cinético, mas alguém que experimenta e prova, ou seja, um experimentador. [...] A valorização atual da arte sempre fica nas mãos de poucas pessoas, que no fim das contas são os grandes colecionadores. Não é anormal que existam, mas o que é anormal é que sejam exclusivamente aqueles que têm muito dinheiro os que exercem essa valorização [valorización] da arte contemporânea (ART DEMOCRACY, 2014, p. 58). 
Em uma palestra de agosto de 1981, em Havana, Le Parc usou o termo "valoração" [valoración] para expressar essa mesma ideia que atravessa toda sua obra, a de que curadores e marchands tornaram-se mais importantes que os artistas (LE PARC, 1985, p. 123). Algo que encontramos tanto em suas primeiras obras-manifestos quanto didaticamente exposto em suas historietas (LE PARC, 1997; LE PARC, 2013). A explicação de seu translado só se completa, portanto, quando levamos em conta, como faz Noé, o sucesso comercial da arte contemporânea a partir do segundo pós-guerra e a institucionalidade que amparou esse sucesso. É justamente esse método de apropriação, iniciado nos anos sessenta e voltado seletivamente para o Le Parc cinético como afronta aos EUA, que vemos culminar nos dias de hoje. ${ }^{3}$ Essa é a trilha histórica aberta pela exposição Lumière et Mouvement, organizada por Frank Popper em 1967, e que chegou à Dynamo: un siècle de lumière et de mouvement dans l'art 1913-2013, dirigida por Serge Lemoine ${ }^{4}$ (1943-).

Também é o que nos confirma o depoimento da diretora de programação do Centre Pompidou Metz, Hélène Guenin, à revista La Nación, justificando a recente aquisição da monumental Déplacement du spectateur n. 1 (1965-2013, metal, chapa de madeira laminada e madeira pintada) de Le Parc para o museu, colocando-o, desde então, ao lado de Pablo Picasso, Fernand Léger, Joan Miró etc.: "Hoje há toda uma nova geração de curadores que volta a se interessar pelo trabalho de reflexão dos cinéticos" (KANTT, 2014).

O encaixe foi perfeito, pois Le Parc já levava multidões a suas exposições, ao menos desde 1966. A ausência de exigências eruditas, do olhar especializado, era extremamente convidativa e perseguida conscientemente pelo artista, como podemos ver no vídeo de sua primeira retrospectiva argentina no Instituto Di Tella. ${ }^{5}$ Esta é a inquietação provocadora de

\footnotetext{
${ }^{3}$ No capítulo IX de sua Antiestética de 1965, Noé já reconhecia o pop como "uma manifestação de que esse desenvolvimento lógico da evolução da arte europeia, em especial a francesa, se quebrou". Bem parecido com o dito pelo crítico brasileiro Mário Pedrosa (1900-1981), treze anos depois: "A pop-art foi, com efeito, entre todas as manifestações que vieram com o movimento modernista desde o cubismo, o construtivismo, o futurismo, o expressionismo, o surrealismo e todos os ismos, a primeira manifestação de arte que surgiu por inteiro como alheia e externa aos preceitos do movimento modernista" (PEDROSA, 1995, p. 344).

${ }^{4}$ Realizada entre 10 de abril e 22 de julho de 2013 , no Grand Palais, a megaexposição dedicou $4.000 \mathrm{~m}^{2}$ (todas as galerias do espaço) à reunião de 142 artistas ou grupos (pintura, escultura, instalações e ambientes visuais) em um contexto de "abstração geométrica", "lumino-cineticismo", arte ótica (op art) e pintura cinética (LEMOINE, 2013, p. 367).

${ }^{5} \mathrm{O}$ vídeo institucional dessa primeira retrospectiva de Le Parc, dirigido por Jorge Alberto de Leon (18min. $16 \mathrm{~mm}, 1967)$, está disponível no sítio oficial do artista: http://www.julioleparc.org/filmographie.html Uma versão ampliada (19'43") pode ser vista no sítio da Serpentine Galleries de Londres: http://www.serpentinegalleries.org/exhibitions-events/julio-le-parc
} 
suas obras: o lúdico, o não erudito, o fim do tabu do "não me toques", como salientou Mário Pedrosa acerca da "sala mágica de Le Parc", apresentada na IX Bienal de São Paulo, em 1967 (PEDROSA, 1995, p. 273). Sua "consagração definitiva" após os 80 anos é, ao mesmo tempo, um sinal de reconhecimento e a da tentativa de convertê-lo em precursor da atual ingestão de arte entre cafés e lojas de badulaques: uma projeção retroativa da exposição como marca.

Meu ponto de vista sempre foi refletir sobre os mecanismos de difusão (da arte), sobre a mistificação do criador e a inserção em um circuito comercial. É imprescindível que o espectador jamais se sinta inferior, que tenha a relação mais direta possível com a obra, sem necessidade de haver estudado estética ou história da arte (ART DEMOCRACY, 2014, p. 59).

Estimulando o consumo, a moda e o predomínio do marketing no espaço antes "sagrado" da arte, esse conceito de "arte contemporânea", apoteose da lógica operatória do capitalismo tardio, pós-moderno, pouco tem a ver com Le Parc, pelo contrário, constitui sua dissolução. Esse jogo de luzes sobre sua biografia, denominado na França por "recuperação" ou "instrumentalização", desloca, pouco a pouco, nossa percepção para o que é apenas um dos reflexos de sua imagem, funcionando mais ou menos como sua obra Cloison à lames réfléchissantes (1966): faz vacilar nossa capacidade de distinguir o autêntico de suas projeções ao expropriar aspectos específicos de sua produção.

Entendamos a sutil complexidade em jogo aqui. A "passagem do capital de mercado ao monopólio" ou "do moderno ao pós-moderno" como caracterizado por Fredric Jameson (2011, p. 234-561), enredou em um mesmo circuito transnacional (controlado por pouquíssimas mãos) os novos mercados de arte, como os latino-americanos, canalizando uma demanda que fez saltar os preços das obras mais recentes e, assim, valorizando artistas ainda em atividade. Durante os anos sessenta, em plena reconstrução europeia, pela primeira vez na história, artistas vivos valiam tanto quanto os maiores nomes do modernismo. Para as galerias essa inflação se demonstrava duplamente vantajosa, pois a mão de obra era barata (por se encontrar em diáspora) e muitas vezes proveniente desses próprios mercados consumidores emergentes, lembrando a perspicaz síntese de Terry Eagleton (1943-): “O migrante viaja pelo mundo, o mundo viaja para o cosmopolita. O migrante não pode ir para casa, ao passo que o cosmopolita não tem casa para onde ir" (EAGLETON, 2011, p. 94). 
Outra evidência, talvez mais enfática, de que Le Parc chegou à Europa, em parte, por não conseguir se firmar como artista devido à ausência de instituições modernas no mercado argentino é o fato de o Instituto Di Tella - que é a primeira instituição moderna de amparo às plásticas naquele país - só ter sido fundado em 1958. O que existia até então era mecenato e galeria (cerca de 40) para os artistas vivos e museu para os mortos. Só quando passa a existir um museu para os artistas vivos é que se pode formular o conceito de "arte contemporânea", que envolve certamente um estilo, mas que designa, antes de tudo, uma função: a obra que dispõe dos dispositivos de valoração capitalista para a arte. Dispositivos cada vez mais concentrados em marcas.

Durante todos os anos sessenta, essa cobiça burguesa inerente à acumulação de capitais esforçou-se por reativar condições arcaicas do mercado de arte tidas como já superadas, gerando algumas consequências obviamente contraditórias. No caso de Le Parc, é o que vemos no contrato de exclusividade firmado com a galeria de Denise René (19132012). Esse contrato, do qual falaremos mais adiante, permitiu-lhe, desde 1959 (ITDT, 1967, p. 7-8), acessar não propriamente os meios de produção de arte, mas os meios de valoração de obras e, assim, desempenhar um papel preponderante na criação de "um novo mapa ampliado da figura da América Latina" (PLANTE, 2013b, p. 48).

A oligopolização dos mercados culturais provocada pelo circuito internacional de bienais e superexposições itinerantes pôs em andamento uma lógica contraditória: a replicação do modo de gestão dos fluxos da vida cotidiana (que é própria ao turismo) como "utopia nômade do consumo", contraposta à condição de migração dos produtores sob constante espoliação. Especificamente em Paris, a pretensão institucional de um mundo “domesticadamente exótico", sem imprevistos, conflitos ou guerra (LONGONI, 2014, p. 94), acabou gerando, à revelia, uma verdadeira frente de luta internacionalista em torno desse conceito emergente de "arte contemporânea".

Retomando nossa ideia anterior, desde que se iniciou essa política econômicofinanceira transnacional, os museus também passaram a ser guiados pela busca de "rendimento monopólico", abrindo uma senda para que eles fossem, direta ou indiretamente, "comercializados por meio das práticas mercadológicas da indústria do turismo" (HARVEY, 2003, p. 142). Estar no centro do mercado capitalista de arte possibilitava aos artistas maior visibilidade em seus países de origem, por mais que a contrapartida 
financeira imediata não fosse a desejada. Nesse novo e contraditório contexto, galerias de médio porte trabalhavam internacionalmente à sombra de bienais, prêmios e grandes exposições públicas, levando alguns poucos artistas, situados em locais específicos, a faturarem milhões. Esse foi o status alcançado pela plástica burguesa no segundo pósguerra: montar um espetáculo fora do qual nenhuma obra persista.

Mesmo Mário Pedrosa, figura de frente das bienais paulistanas, reconheceu, em 1970, que com o tempo as bienais passaram a agir como "as escolas de arte, as academias, os museus", ou seja, como "instrumentos de glorificação do estado presente da arte e do resto das superestruturas" (PEDROSA, 1995, p. 275). Analisando com a mesma atenção as relações institucionais desse processo "vanguardista" ocorrido na América Latina, e que teve como período decisivo os anos 60, Néstor Garcia Canclini (1939-) elaborou o conceito de "modernidade depois da pós-modernidade", segundo o qual a burguesia industrial assume a modernização do modo de produção pela introdução de novos hábitos de consumo e padrões culturais "que ela mesma impulsiona, com fundações e centros experimentais destinados a conquistar para a iniciativa privada o papel de protagonista na reorganização do mercado cultural" (CANCLINI, 1990, p. 227).

A dimensão assumida pela institucionalidade da arte, no início dos anos sessenta, faz então emergir eventos ligados tanto à desativação da obra quanto à institucionalização das vanguardas que, antes de serem meros índices de "democratização" da arte, inseriam-se em um projeto mais amplo que dizia respeito às disputas pela homogeneização e aburguesamento das massas populacionais nos grandes centros urbanos (gentrification). 0 "museu líder", público, foi rapidamente acomodado a esta lógica para aperfeiçoar a coexistência aparentemente conflitiva entre tradição e vanguarda.

Essa nova etapa vanguardista de grupos conciliados não tanto com a tradição artística ocidental, mas com suas instituições, surgiu em meados dos anos 1940. Sendo também chamadas por "vanguardas cosmopolitas" ou, depois, "pós-modernas", elas se distinguem com facilidade da primeira floração de futuristas, dadaístas e surrealistas. Seus manifestos são geralmente exposições teóricas com finalidade didática e legitimadora, não 
panfletos incendiários como os de outrora, constituindo o que os membros do GRAV 6 chamarão "nova moda" internacional e cuja consagração se dará com o pop. Elas se apresentaram historicamente como rituais de transição, muitas vezes traumáticos, da alta cultura aos mass media, para fazer triunfar uma individualidade distópica e descentrada própria ao ultraindividualismo dos anos 1970 em diante. ${ }^{7}$ E também podem ser qualificadas como "retrospectivas" porque, quase sempre, projetaram sua ancestralidade nas chamadas "vanguardas construtivas" do início do século, as quais são o complemento e antípoda das vanguardas históricas (Cf. BÜRGER, 2008).

Esse é o sentido liberal da evocada "democratização" que partiu o mercado de arte em dois: um circuito de grandes instituições de museus e outro de curadores independentes e seu lobby. "A mostra de arte passa a ser feita de arte, e os marchands passam a dominar. As leis do mercado capitalista não perdoam: a arte, uma vez que assume valor de troca, torna-se mercadoria como qualquer presunto" (PEDROSA, 1995, p. 221). O ciclo adaptativo da arte burguesa após o abalo vanguardista - afinal "as vanguardas históricas além de demandarem a eliminação do passado, praticavam a destruição semiológica de todas as formas tradicionais de representação" (ARES, 2006, p. 22) - se encerrava vitorioso.

A leitura conveniente que vê nesse modus operandi (a cultura submetida à lógica administrativa do capitalismo avançado) o vetor de uma democratização acompanhada de crítica institucional, não vai muito além do mascaramento de sua nova função. Tanto a "democratização" que se expressa na aproximação entre público e museus, quanto a "crítica" deduzida da progressiva indistinção entre público e obras, jamais significaram qualquer diminuição da distância entre público e arte. Pelo contrário, a "desativação da obra" no período conferiu poderes ainda maiores à instituição, ao substituir a aura da arte modernista (relativamente autônoma) por outra muito maior (publicidade/mass media). Estamos falando da inserção da arte na gestão profissional dos fluxos da economia simbólica em sociedades capitalistas desenvolvidas, o que significa o estabelecimento de uma

\footnotetext{
${ }^{6}$ Group de Recherche d'Art Visuel [Grupo de pesquisa de arte visual, 1960-1968], integrado por Horacio García Rossi (Argentina, 1929-2012), Julio Le Parc, François Morellet (França, 1926-), Francisco Sobrino (Espanha, 1932-2014), Jöel Stein (França, 1926-2012) e Jean-Pierre Yvaral (França, 1934-2002).

7 Podem ser consideradas algumas das principais "neovanguardas" das artes visuais latino-americanas: espacialismo, concretismo, madí, perceptismo, cinetismo, neoconcretismo e conceitualismo.
} 
tecnocracia gestora de signos-mercadorias em um âmbito mais geral do processo material de forja histórica das subjetividades, a qual denominamos por "cultura".

Desmistificar a arte (burguesa) e denunciar a opressão (capitalista)

Refaçamos a cronologia aprofundando a análise. Le Parc ingressou aos 15 anos (1943) na Mutualidad de Estudiantes de Bellas Artes da Escuela Nacional de Bellas Artes de Buenos Aires (DUJOVNE, SOLÁ, 1967, p. 25). Em 1947 abandonou os estudos, o trabalho em uma fábrica metalúrgica e rompeu com a família: "Vive um pouco à margem, frequenta anarquistas e marxistas e passa a analisar seus problemas de um ângulo diferente. Como vagabundo viaja ao interior do país. Trabalhando de tempo em tempo como pedreiro ou operário em oficinas metalúrgicas" (CATÁLOGO, 1988, p. 191). Em 1955 retorna à Belas Artes $^{8}$ e em 1958 conseguiu uma bolsa no concurso do governo francês (oito meses, renovada por mais oito), via embaixada, e depois a do Fondo Nacional de Artes Plásticas (um ano), por intervenção de Julio Payró (1899-1971). Ainda em 1958 foi criado o Instituto Torcuato Di Tella como instituto de pesquisa em ciências sociais e artes, independente das universidades.

Apenas em 1960 foi fundado o setor de artes do ITDT, com direção de Enrique Oteiza, funcionando inicialmente em uma pequena sala do Museo Nacional de Bellas Artes. Mesmo ano em que foi criado o GRAV, contando com onze nomes em sua primeira formação. Em 1961, o grupo passou a ter apenas seis integrantes e Le Parc já acumulava participação em três bienais (São Paulo, 1957, Bienal Hispano-americana-México, 1958 e Paris 1959). Somente em 1963 foi inaugurado o Centro de Artes Visuais do Instituto Di Tella, sob a direção de Jorge Romero Brest (1905-1989), na Rua Florida, próximo à Praça San Martín, consolidando-se como centro moderno de arregimentação cultural, intelectual, estudantil, artística e boêmia da cidade. Neste mesmo ano, Le Parc ganhou a Medalha de Ouro na Bienal de San Marino e primeiro prêmio na de Paris. Este ano foi, a um só tempo, o da consagração oficial do GRAV e o início do caminho lúdico a partir de seu Labirinto (Bienal de Paris).

\footnotetext{
${ }^{8}$ Mais de um documento (especialmente os datados de 1968) encontrado no "Sobre" de Julio Le Parc (30 catálogos e 103 fólios), no arquivo da biblioteca do Museo de Arte Moderno de Buenos Aires, apresentam-no como "professor superior de desenho e pintura".
} 
Em 1964, o crítico francês Pierre Restany (1930-2003), o estadunidense Clement Greenberg (1909-1994) e o próprio Romero Brest (que também foi jurado nas bienais de São Paulo em 1961, Veneza em 1962 e Paris em 1965), formaram o júri do Prêmio Nacional e Internacional do Instituto Di Tella, que concedeu prêmio em dinheiro para o primeiro colocado internacional: Julio Le Parc. Mas existia, já naquela época, uma evidente discrepância entre as pretensões leparquianas e o que interessava aos críticos que lhe premiavam, como também já ocorria entre o artista e sua galerista. Provavelmente consciente das circunstâncias, Le Parc reproduziu no catálogo da referida exposição nada menos que o manifesto "iBasta de mistificaciones!" do GRAV.

Neste documento, ${ }^{9}$ de outubro de 1963 , distribuído junto ao Labirinto, na bienal de Paris, os artistas do grupo reconheciam a continuidade do fechamento elitista do circuito atual de arte (mesmo da arte de vanguarda) com relação ao público e propunha como alternativa para a superação desse impasse, romper com as principais categorias mistificadoras da arte que acabam por afastá-la das massas populares. Trata-se das mistificações relativas à obra de arte, ao artista único e aos "grupos considerados como superindivíduos". Com ironia, os integrantes registraram: "Se há uma preocupação social na arte atual ela deve ter em conta uma realidade bem social: o espectador". Por isso o esforço da equipe, notado aqui pelo caso de Le Parc, é "tirar o espectador de sua dependência apática" com relação à apresentação da ideia do belo. Segundo eles, é isso que acaba por tornar o público passivo, não apenas para a arte, mas para todo sistema de vida existente, dotando-o de "um complexo de inferioridade" que agrada muito aos artistas que passam a se sentir como pessoas especiais, como "profetas".

Esta passagem do manifesto, que menciona a necessidade de se romper com a passividade e o sentimento de inferioridade do público, comprova, uma vez mais, a continuidade dessa ideia acerca do peso do sistema de arte sobre as obras individuais, que atravessa a produção do argentino, transcendendo, portanto, a periodização que vai de sua chegada à Europa à dissolução do GRAV. Ela se iniciou em 1955, durante o levante estudantil na Escola de Belas Artes, como apontou Jean-Louis Pradel (1946-2013). Para o crítico e historiador francês isto transparece em sua Historieta, um tipo de bande dessinée que

\footnotetext{
${ }^{9}$ Trata-se da tradução do manifesto "Assez de mystifications 2". Seu antecessor, "Assez de mystifications 1", é substancialmente distinto, foi redigido em setembro de 1961 e apresentado na II Bienal de Paris.
} 
tomou forma a partir de 1978, mas cujo princípio de execução se deu ainda na Argentina e adquiriu concretude com as ações do GRAV. ${ }^{10}$ Meia década antes dos acontecimentos do maio parisiense de 1968, ao grupo já não importava mais a obra de arte, mas a "contestação do sistema cultural".

O que interessava era, sobretudo, a atitude do artista, por isso eles denunciavam o vazio da experiência passiva do público que não serve, senão, ao preenchimento por especialistas que se tornam, por iniciativa própria, mediadores entre obra e público. Desde então os objetivos básicos do grupo passaram a ser a "reconsideração do ato criador superestimado" e a "revalorização do espectador" pela "comunicação e interação". Algo bastante visível desde o Labirinto coletivamente preparado: uma forma de eliminação da distância obra-espectador que também parece estar presente nos Penetráveis de Jesús Rafael Soto (1923-2005), mas com diferenças.

A crítica e escritora Marta Traba (1930-1983) foi quem observou, no final da década de setenta, a distância entre as propostas. Soto se desinteressava "por carregar a obra de qualquer outra potencialidade além da que encerra sua própria forma", o avesso da desaparição deste hiato (criação-recepção) no GRAV. Enquanto nos argentinos/franceses o esforço consistia na desintegração da impotência do público ante a obra e, consequentemente, a ruina do artista como "criador", no venezuelano, o jogo de relações estrutura "uma obra sem ambições de projetar-se, nem sobre a sociedade, nem sobre o receptor individual"11 (TRABA, 1978, p. 91). Comparemos com o que dizia o referido manifesto distribuído junto ao Labirinto.

\footnotetext{
${ }^{10}$ Segundo relata-nos o próprio Le Parc, na introdução à sua Historieta: petite histoire en images interrogeant la face cachée de l'art, de l'artiste et de son contexte social, foi durante a ocupação da Escola de Belas Artes em Buenos Aires, que ele criou os primeiros textos com desenhos humorísticos tematizando o meio artístico e o ensino de arte; uma "análise embrionária do meio artístico [que] se aprofunda em seguida no seio do Groupe de Recherche d'Art Visuel" (LE PARC, 1997, p. 12).

11 Damián Bayón, em texto da mesma época, destaca ainda mais as diferenças entre a consagração venezuelana e a "evolução ao contrário" (anticinética) dos argentinos. Almejando rastrear sua determinação, o crítico escreve: "Eu atribuo o êxito e a permanência de Soto, Cruz-Diez (e agora também de Otero) não apenas a uma questão de talento pessoal, e sim, igualmente, ao apoio que o Estado e as empresas privadas venezuelanas the conferiam, transformando-os em verdadeiros heróis nacionais, cheios de encargos de responsabilidade. Os argentinos, talvez por falta de resposta, oficial ou privada, foram sendo apagados do mapa artístico de uma vanguarda em plena realização" (BAYÓN, 1978, p. 121-122). O que para Bayón era uma desconfiança ("talvez por falta de resposta"), está subentendido como certeza no trabalho de Traba que vai mais longe ao tentar explicar o que essa resposta (uma "plástica hegemônica") implica socialmente (TRABA, 1978).
} 
Nós queremos inspirar o espectador, tirá-lo de suas inibições.

Nós queremos fazê-lo participar.

Nós queremos que ele seja consciente de sua participação.

Nós queremos colocá-lo em uma situação que o provoque e transforme.

Nós queremos que ele se direcione a uma interação com os outros espectadores.

Nós queremos desenvolver no espectador uma forte capacidade de percepção e ação.

Um espectador consciente de seu poder de ação e cansado de tantos abusos e mistificações poderá fazer ele mesmo a verdadeira "revolução em arte".

Ele porá em prática as consignas:

Proibido não participar

Proibido não tocar.

Proibido não romper (ITDT, 1964, 56-57).

Em 1966, Le Parc venceu a 33a bienal de Veneza como representante da Argentina, com seus mais de quarenta objetos manipuláveis e obras cinéticas: Continuos-móviles, Continuos-Iuz, Contorsiones, Tramas, Desplazamientos, Pasajes, Espejos, Anteojos para una visión otra, Zapatos para un andar otro. O grande prêmio de pintura ia para um argentino que não pintava, mas fazia coisas parecidas às salas de jogos apresentadas pelo GRAV em Paris. Nas palavras de Jean-Louis Pradel, "gadgets espaço-dinâmicos e cinéticos", ou, nas de García Canclini, máquinas e óculos cinéticos que "multiplicam as formas do real, mostram suas facetas móveis, a pluralidade possível de pontos de vista, a fugacidade caleidoscópica e contraditória do mundo" (CANCLINI, 1979, 10).

Essas obras tentavam, já em seus títulos, colocar em interdição a naturalidade das percepções cotidianas: exposição a estímulos ópticos e táteis, integração e manipulação das obras, além da existência dos múltiplos. Não estavam sendo problematizadas apenas as belas artes, mas a vida do dia-a-dia que se vê progressivamente automatizada. E por mais que os materiais mobilizados nos múltiplos tenham "alguns pontos em comum com os produtos do desenho industrial", não é tanto com o "desenho moderno da Escola de Ulm e suas preocupações sobre o perfeito encaixe entre forma e conteúdo, mas com o styling" (PLANTE, 2013b, p. 134). Novamente segundo Pradel, Le Parc sempre privilegiou a pesquisa no lugar do estilo, o engajamento no lugar da carreira profissional, o que levou o próprio Le Parc a se definir, em 1996, como um "plasticien expérimentateur" (LE PARC, 1997, p. 14).

Em 1967 ocorreu a prestigiada Lumière et Mouvement, na qual 14 dos 39 artistas eram latino-americanos, e Marc Pessin (artista e editor) organizou uma exposição, em Sant- 
Laurent-du-Pont, próximo a Grenoble, reunindo quatro argentinos, entre eles Le Parc. No ITDT, Brest preparou a primeira retrospectiva argentina do artista, com visitação de quase 160 mil pessoas, em uma estimativa de 08 mil ao dia, entre 01 e 20 de agosto, na calle Florida 936 (Exposição 48 do CAV-ITDT). Antecipando-se a isso, em 1966, Denise René, que já havia trabalhado com produção seriada (serigrafia e tapeçaria), montou uma segunda galeria, na Rive Gauche, exclusivamente para a comercialização dos "múltiplos" como os produzidos por Le Parc e seu grupo.

O termo "múltiplos", que se tornou uma patente dessa galerista, designa o tipo de produção seriada que tem ancestralidade no geometrismo produzido por Victor Vasarely (1906-1997), pai de Jean-Pierre Yvaral, um dos membros do GRAV. Mas com um diferencial significativo, a ideia de desmistificação da arte junto à "tiragem ilimitada, da qual os membros do GRAV eram partidários", colocavam "novos problemas ligados ao sistema de distribuição e ao status da obra de arte" (PLANTE, 2013b, p. 137), provocando conflitos crescentes com René, que também era a dona de quase todas as obras lumino-cinéticas de Le Parc premiadas em Veneza. Em troca, um salário mensal de 300 francos, mesmo valor que recebia como bolsista. ${ }^{12}$

Na exposição no Di Tella, na qual foi apresentado um total de 58 obras (algumas com muitos exemplares), ficou mais uma vez evidente que, por mais que existisse em Le Parc um interesse plástico derivado tanto do concretismo quanto do espacialismo de Lucio Fontana (1899-1968), sua atividade se construía fundamentalmente como crítica às tendências construtivistas e mesmo cinéticas. Ela consistia numa ruptura com a derivação decorativa e comercial da pintura geométrica da década de $1950 .{ }^{13}$ Diferenças que desde Lumière et Mouvement, organizada por Frank Popper, tendem a se embaçar mais e mais. Ou seja, pouco adiantou Le Parc e seus companheiros manifestarem, desde o início das atividades do GRAV (1960), um claro distanciamento com relação à "atitude dos artistas que

\footnotetext{
12 Em 1966, o artista afirmou: "[A bolsa] Durava oito meses e eram, mais ou menos, 17 mil pesos argentinos mensais. Como não fumo nem bebo, passava raspando" (CONFIRMADO, 1966, 74).

${ }^{13}$ O geometrismo dos anos cinquenta argentino começou a ser sistematizado em 1944, com o lançamento da revista Arturo. Em 1945 foi criada a associação Arte Concreto-Invención e em 1946 a revista homônima. Ainda em 1946, formou-se o grupo Madí e, incentivado por Romero Brest, seu sócio na Academia de Altamira, Lucio Fontana lançou o "Manifiesto Blanco", após discuti-lo com seus alunos. Em 1948, finalmente, realiza-se a exposição Novas Realidades que congrega concretos, madis e independentes (BAYÓN, 1978, p. 117-118). Desse aglomerado surgiram a geometria sensível dos anos seguintes e essa variante a que nos referimos.
} 
utilizam a livre escolha de formas e sua livre localização em uma superfície e no espaço" (ITDT, 1967, p. 7).

\section{América Latina Não Oficial: contrainformação e denúncia}

É desse modo perceptível como um mesmo aspecto - a desmistificação da obra interessava aos distintos agentes da nova fase das artes plásticas na América Latina, Estados Unidos e Europa. Especialmente se levarmos em conta que o processo desencadeado pela ação do Instituto Torcuato Di Tella não estava isolado, mas articulado a outras iniciativas regionais como as das indústrias Matarazzo em São Paulo, da Esso na Colômbia, da General Electric em Montevidéu, do Acero del Pacífico, no Chile, ou do Instituto Nacional de Cultura em Lima. Apesar da diferença de discursos, por exemplo, entre Romero Brest (um liberal conservador que gostava de afirmar, "no Di Tella não permiti nunca que se fizesse política") e Mário Pedrosa (que desempenhou papel equivalente no Brasil como promotor da associação Rockefeller-Francisco Matarazzo Sobrinho), ambos estavam igualmente fascinados pela alternativa oferecida por Le Parc ante o esgotamento da arte moderna.

O fato de o Di Tella jamais ter feito política foi, certamente, decisivo no encerramento de suas atividades artísticas no início dos anos 70.0 instituto e seu diretor, Romero Brest, recebiam sucessivas críticas, da esquerda à direita, tanto de intelectuais que passavam por um processo crescente de nacionalização e peronização, quanto da esquerda tradicional (realista, anticosmopolita ligada ao PC) ou da nova vertente da vanguarda artístico-política que, desde o golpe de 1966, radicalizou sua atuação ante a ditadura Onganía. Para se compreender esse posicionamento aparentemente ímpar da instituição, deve-se recordar que - além de ter fundado a Academia Altamira, ${ }^{14}$ criado a revista Ver $y$ Estimar (1948), realizado palestras no Brasil (em 1948, 1951 e 1953) e de ter envolvimento habitual com o novo regime de bienais e premiações incentivadas por agências transnacionais - seu principal animador, Brest, a partir de 1963, tornou-se presidente de uma filial do Conselho Internacional do MoMA de Nova Iorque, presidido por David Rockefeller (1915-).

\footnotetext{
${ }^{14}$ Escola privada de ensino de arte fundada com Emilio Pettoruti (1892-1971), Jorge Larco (1897-1967) e Lucio Fontana. Segundo Antje Kramer, a escola constituirá "um campo magnético para os novos artistas que colocará as pesquisas da arte concreta na ordem do dia" (KRAMER, 2011, p. 164).
} 
O objetivo desse conselho era "fazer mais íntimas as relações que unem os países americanos e tornar mais estreita a colaboração que se pode prestar mutuamente", como prescrito pelas palavras de Waldo Rasmussen (1928-2013), diretor executivo de exposições do MoMA (ARES, 2006, p. 27). Ainda cumpre mencionar que o Instituto de Brest recebia regularmente verbas da Alliance for Progress (criada pelos EUA, em 1961, como resposta à Revolução Cubana e à efervescência contracultural por ela deflagrada), da Ford Foundation e da Rockefeller Foundation. Segundo Canclini, entre os anos 1960-1968, os investimentos dos Estados Unidos na Argentina aumentaram 243\%. A montagem, ainda que longa, de três excertos do autor esclarece:

A penetração maciça do capital industrial norte-americano é acompanhada, no terreno cultural, de financiamentos das fundações Ford e Rockefeller, destinados a promover pesquisas sobre temas de interesse para a nova etapa socioeconômica e a estimular as orientações teóricas predominantes nos Estados Unidos. [...] A penetração cultural norte-americana na América Latina também iniciou uma nova etapa nas artes plásticas durante os anos 50. A criação de um Conselho Internacional por parte do Museu de Arte Moderna de Nova lorque (1952), que exportou mostras de pintura norteamericana de vanguarda para as principais capitais do nosso continente, 0 apoio econômico da União Pan-americana, da CIA e das empresas multinacionais (Esso, Standard Oil, Shell, General Motors, General Electric) a museus, revistas, artistas e críticos latino-americanos, configuraram uma agressiva campanha que, por diversas vias, às vezes encobertas, promovia um mesmo projeto: difundir uma experimentação formal aparentemente despolitizada, sobretudo o expressionismo abstrato, como alternativa ao realismo social, ao muralismo e a toda corrente preocupada com a identidade nacional dos nossos países. [...] O Instituto Di Tella e seu diretor, Jorge Romero Brest, mostraram-se francamente favoráveis à penetração norte-americana (CANCLINI, 1979, p. 84-85).

Mas isso não se restringia a Pedrosa ou Brest. No segundo pós-guerra, cada um dos mais distintos teóricos, artistas ou mesmo comerciantes de arte que portasse uma crítica à herança artística modernista, independentemente de sua localização na nova lógica do imperialismo transnacional, parecia encontrar em Le Parc uma solução possível. O mesmo se deu com Pierre Restany e é o que também encontramos em Frank Popper: movimento e luz tornaram-se "meios importantes de expressão artística" (ITDT, 1967, p. 12). Aqui voltamos a rondar a questão não resolvida (que se tornará insustentável) entre Le Parc-GRAV e os movimentos anteriores na Argentina ou na Europa, o que redundará no fim do próprio grupo. 
No fim dos '60, as experiências de vanguarda "eram associadas em bloco ao Instituto Di Tella e acusadas de frívolas, passadistas, despolitizadas e estrangeirizantes" (LONGONI, 2014, p. 41-42), além de reconhecidas como claramente elitistas. Um exemplo dessa contiguidade das aparências está na pesquisa com novos materiais (fibra de vidro, acrílico, plástico, poliéster, alumínio) e novos processos tecnológicos (iluminação, eletrônica e multiplicação seriada) que existia no GRAV, mas que pouco tinha a ver com o slogan defendido por Brest: "cosmopolitismo, alegria e ócio". Isso fez com que o afastamento crítico fosse se tornando imperativo a quem quisesse dissociar as imagens.

Marta Traba - que depois falaria em uma "cultura do êxodo" para descrever o período - também já havia criticado esse corte representado pela instalação de um centro de pesquisa experimental (como se propunha a ser, desde o início, o ITDT) antes da existência de um Museu de Arte Moderna na cidade. Durante a década de 50, especialmente após o período de forte contestação (1955) promovido por estudantes de artes nas instituições oficiais de ensino (do qual Le Parc fez parte) eram esboçadas algumas iniciativas com esse propósito.

Foi fundado, por Marcelo de Ridder, o Instituto de Arte Moderno, gestor de uma importante coleção de artistas argentinos contemporâneos que, posteriormente, serviu como base para o Museo de Arte Contemporáneo, instituição privada que funciona na cidade desde 1977. Nesta mesma década de 50, mais precisamente em 1955, foi criado por iniciativa de Rafael Squirru, o inicialmente itinerante (porque desprovido de sede própria) Museo de Arte Moderno ${ }^{15}$. Fatos que indicam o quanto os artistas argentinos ainda estavam em uma fase incipiente (mas efervescente) de conhecimento mútuo e influência recíproca. Nas palavras de María Cristina Ares: "não havia, em nosso país, retaguarda alguma, então, [Marta Traba] a lê como uma vanguarda no vazio e, por fim, totalmente inoperante e completamente a-histórica" (ARES, 2006, p. 28).

\footnotetext{
${ }^{15}$ Até 1960, data em que se transfere para o Teatro Municipal San Martín, o MAM só existiu num papel que seu diretor carregava no bolso (LONGONI, MESTMAN, 2013, 47), realizando suas mostras em galerias privadas, ateliês de artistas, praças e até garagens. Rafael Squirru também foi diretor de assuntos culturais da OEA e participou, em 1963, da criação do Inter-American Commitee (IAC), uma associação que propunha arte e cultura como "armas da Guerra Fria" a partir do intercâmbio, uma forma de propaganda anticomunista (lê-se estadunidense). $\mathrm{O}$ encontro originador do IAC, sugestivamente realizado no paraíso fiscal de Bahamas, previa a necessidade do uso de investidores [inversores], agentes culturais e organizações do governo como a CIA para a adequada realização de seus objetivos (GIUNTA, 2001, 246).
} 
Surgia com o ITDT uma vanguarda cujas ações "redefinem o campo artístico e implicam uma ruptura com o cânon dominante", mas que ia além. Essa oficialidade experimental reformulava a função social dos artistas na mesma proporção em que, por meio de uma normatividade severa, os colocava em sintonia com os mais sofisticados centros mundiais. $\mathrm{O}$ instituto se caracterizava, assim, por "institucionalizar o rebelde para depois, por essa mesma razão, deixá-lo cair" (NOÉ, 2009, p. 300). Uma força que, simultaneamente, impôs tendências, estandardizou gostos e inclinações (valores), e se apropriou do sentido do "circuito modernizador" emergente. Dito de maneira distinta, por meio da filantropia, surgiu na Argentina um mecenato moderno, com ligações internacionais, "em que a relação entre o empresário e o artista já não é direta, mas está mediada por uma gestão profissionalizada com certo grau de autonomia" (LONGONI, MESTMAN, 2013, p. 43). Por isso Andrea Giunta reconhece, na mesma trilha de Canclini, a divulgação norte-americana após o expressionismo abstrato como um "instrumento de neocolonialismo na América Latina" (GIUNTA, 2001, p. 31).

No caso específico do Di Tella, ele modernizava, sobretudo, o modo de financiamento e, para usar um termo caro a Le Parc, de "valoração" de obras que, como já vimos, se repetia por todo o continente com interesses bem precisos. "O Di Tella inventou uma estética do deterioro. Se consome uma coisa e depois tem que mudar" (TRABA apud NOÉ, 2009, p. 306). Por isso foi ficando cada vez mais claro para Le Parc que "o problema da arte latino-americana não pode ser colocado em termos estéticos" (LE PARC, 1985, p. 123), pois a valoração se refere à obra de arte sempre correlativamente à cultura que nela se torna visível, isto é, a obra está conectada a algo maior que a história da arte.

Assim, podemos dizer que o Di Tella influiu decisivamente na dinamização da produção e do consumo cultural ao agir na esfera da circulação, incentivando com parcialidade manifesta aquilo que se compreendia entre a nueva figuración e a arte cinética, passando pela abstração, pela arte geométrica e experiências próximas à da arte pop, como o minimalismo e o conceitualismo (LONGONI, MESTMAN, 2013, p. 45). A saída para a rua no GRAV, com Une journée dans la rue (19 abr. 1966), mesmo que não tenha logrado o resultado esperado, foi uma tentativa de contornar essa situação que tomava ares de modismo institucionalizado. 
O relato que Isabel Plante faz do comentário de Restany a respeito do baixo impacto das situações criadas pelos "parênteses lúdicos" do GRAV (Une journée dans la rue), deixa claro como a experiência de contato direto com o grande público (sem a apelação aos meios de comunicação ou ao sistema artístico) desencadeava, mesmo por seu fracasso, uma nova consciência: “Opéra resultou, para Restany, um tanto decepcionante, pois pouca gente reagia diante dos penetráveis de onde se podia 'ver tremer o mundo'. Ninguém parecia disposto a perder o metrô, exceto alguns turistas que se detiveram a tirar umas fotos" (PLANTE, 2013b, p. 157). Restany estava certo, mesmo que seu objetivo fosse a defesa da autonomia estética, pois a conclusão a que chegou foi que o efeito das obras nas ruas não era o mesmo, uma vez que faltava aos populares a chave interpretativa do olhar culto, ou o contexto de onde deduzi-la, demonstrando a permanência da distância entre arte e vida.

Mas sair à rua era uma necessidade, especialmente porque já estava ficando óbvia a relação subjacente à fascinação espetacular do lumino-cinetismo tecnológico nas salas de exposições financiadas por empresas ligadas ao setor automobilístico e de eletrodomésticos. Sem falar do mal-estar permanente dos múltiplos que agora eram vendidos na FNAC junto a inúmeros outros gadgets. Uma saída que só daria seus frutos mais maduros na década seguinte, com o direcionamento contrainformativo da comunicação direta com o público na exposição Amérique Latine Non Officielle ${ }^{16}$ e na série de atividades que Ihe seguiram (refuncionalização). Por isso a continuidade das atividades do GRAV tornava-se simplesmente insustentável, levando-o à dissolução em 1968.

Como dissemos no início, pode-se constatar que na década de sessenta, diversos grupos de artistas, associações, movimentos e salões coletivos surgiram em Paris como tentativa de resistência às transformações ocorridas na vida artística francesa após a ascensão da arte estadunidense no segundo pós-guerra. Nas plásticas parisienses, esse processo foi iniciado com a nouvelle figuration, o Salon de la Jeune Peinture (especialmente a partir de 1965), passando pelo Atelier Populaire (1968), pela Coopérative des Malassis (1970-1981), pelo Front des Artistes Plasticiens (FAP, 1971-1977), pelo Collectif Antifasciste (1974-1977) e inúmeros outros subgrupos. A dissolução do GRAV deve muito a estes eventos

\footnotetext{
${ }^{16}$ Uma análise/reconstituição detalhada da exposição foi realizada por Isabel Plante em seu artigo "Amérique Latine Non Officielle o París como lugar para exhibir contrainformación" (PLANTE, 2013a, 58-84).
} 
alternativos que se não demonstravam maior astúcia de ação, permitiam uma radicalização da abordagem cultural exigida pelo contexto.

No caso de Le Parc, essa guinada coincide com as especificidades dos estágios migratórios argentinos. Ao "processo demográfico de migração" dos 60 , corresponde sua experimentação plástico-sensorial; à ação do "terrorismo de Estado", a politização, ambas vinculadas pelo teor utópico. Não é mera coincidência o que vemos no referido trabalho de Marina Franco: a necessidade de captar a especificidade migratória dos anos 70 reafirma, por inversão consciente, uma continuidade com a década anterior. A diferença, no entanto, reside na participação do "terrorismo de Estado", a partir da Junta Militar, o que implica reconhecer que as forças políticas ocasionadoras da ditadura e do exilio em massa, não poderiam ser em nada alheias à tradição política argentina. $O$ amadurecimento desse êxodo pela ação estatal, que culminou na constituição de um "Estado desaparecedor", foi quem impôs a necessidade de se arregimentar uma "política de comunicação diretamente dirigida à tarefa de solidariedade em favor das vítimas (presos, torturados, desaparecidos) e contra a ditadura militar argentina" (FRANCO, 2004, §1). É o que vemos a partir de América Latina Não Oficial (1970).

Se existir alguma utilidade em complementar as ideias da autora (que não está falando apenas de migração artística), com ilações próprias ao campo da arte ou sob o ponto de vista da produção de Julio Le Parc, podemos dizer que diferentemente do que ocorria com a militância política ou setorizada nos Direitos Humanos, para muitos artistas esse não foi apenas o momento de lutar contra os ditadores no poder, de "informar e testemunhar". Foi também um momento em que se explorou utopicamente essa luta a fim de convertê-la em enfrentamento anticapitalista radical. O objetivo, que adquire forma em América Latina Não Oficial, era criar um modelo passível de ser generalizado, englobando tanto um conceito de totalidade, quanto de universalismo internacionalista que deveria ser apresentado pela prática. Eis a marca de suas obras dos anos seguintes.

O processo de autoconsciência da condição de exilado em Julio Le Parc, que só tomou forma manifesta nos anos 70 , é, ele próprio, a prova da diferença existente entre migração e exílio como modalidades complementares do êxodo, e que têm seu anverso no cosmopolitismo elitista. O próprio Julio Le Parc reconheceu, repetidas vezes, que a desativação da obra na tentativa de "desmistificar a arte" - e assim deflagrar uma crítica 
cultural - nos tempos do GRAV era uma atitude que já portava em si um questionamento crítico e, a sua maneira, utópico. A dessacralização da cultura exigia o desmascaramento da passividade contemplativa do espectador como um resquício religioso na estética burguesa, mas que não foi capaz de instaurar a partir de si uma nova práxis. Pensadas nestes termos, a organização grupal como tentativa de anulação da autoria individual, a coletivização do processo criador, a produção de manifestos e intervenções tornam-se índices de uma preparação inconsciente das condições de superação do presente, como antecipação de algo ainda inominado e cuja importância é maior que a simples politização dos conteúdos. Esse é certamente um ponto determinante para se pensar a obra de Julio Le Parc.

A busca de uma universalidade, no sentido da abordagem do público sem recorrer à particularidade de um repertório especializado (o das artes plásticas), implicou um engajamento com a práxis que abriu espaço para a formulação de uma poética de denúncia e luta internacionalista capaz de articular diferenças regionais em um padrão significativo, em uma narrativa. Para Julio Le Parc, a forma artística, mesmo aquela que denuncia e politiza, não apenas delimita o conteúdo a ser subjetivado, como condiciona integralmente o modo de sua subjetivação. Foi dessa consigna que surgiram novas obras como Façam cair os mitos (1969, três panos 2,5 m em ambiente 05 x 04 m), primeiro "jogo-pesquisa" (jeuxenquetes ou juego encuesta) apresentado por Le Parc e que depois foi repetido em Escolha seus inimigos (1970) e Golpeiem os oficiais (1971, $02 \times 06$ × 04 m), pavimentando o caminho para sua radicalização na década seguinte junto a outros artistas envolvidos no Front des Artistes Plasticiens, no Grupo Denuncia e no Collectif Antifasciste.

\section{REFERÊNCIAS BIBLIOGRÁFICAS}

AMARAL, Aracy. Dos modernistas aos cinéticos: da ferocidade criativa de Matta ao Espaço Latino Americano. In: Artistas latino-americanos de Paris. São Paulo: MAC-USP, 1985.

ARES, María Cristina. Museo y vanguardia. In: SARTI, Graciela C. Vanguardias revisitadas: nuevos enfoques sobre las vanguardias artísticas. Buenos Aires: Van Riel, 2006, p. 13-30.

[ART DEMOCRACY] Pequeño Le Parc ilustrado. Art Democracy, n. 3, Buenos Aires, septiembreoctubre de 2014, p. 52-62.

BAYÓN, Damián. A geometria sensível: uma vocação argentina. In: PONTUAL, Roberto (org.). América Latina: geometria sensível. Rio de Janeiro: Jornal do Brasil/GBM, 1978, p. 115-125.

[BULLETINS] de la Jeune Peinture n. 1, de outubro-dezembro 1975, 39p. 
BÜRGER, Peter. Teoria da vanguarda. Trad. José Pedro Antunes. São Paulo: Cosac Naify, 2008.

CANCLINI, Néstor García. La Modernidad Después de la Posmodernidad. In: BELLUZZO A. M. M. (org.). Modernidade: vanguardas artísticas na América Latina. São Paulo: Memorial, Unesp, 1990.

A produção simbólica: teoria e metodologia em sociologia da arte. Trad. Gloria Rodríguez. Rio de Janeiro: Civilização Brasileira, 1979.

[CATÁLOGO] Julio Le Parc: experiencias 30 años (1958-1988). Buenos Aires: Secretaria de Cultura de la Nación, Ministerio de Relaciones Exteriores y Cultura, 1988.

COGGIOLA, Osvaldo, BILSKY, Edgardo. História do movimento operário argentino. São Paulo: Xamã, 1999.

[CONFIRMADO] Julio Le Parc: cinetizar las massas. Confirmado (Opiniones). Buenos Aires, 1 dez. 1966, p. 74.

DUJOVNE Marta; SOLÁ, Marta Gil. Julio Le Parc: entrevista grabada, documentación y textos reunidos por Marta Dujovne y Marta Gil Solá. Buenos Aires: Estuario, Celección Arte y Crónica, 1967.

EAGLETON, Terry. A ideia de cultura. Trad. Sandra Castello Branco. 2a ed. São Paulo: Editora Unesp, 2011.

FRANCO, Marina. Testimoniar e informar: exiliados argentinos en París (1976-1983). Amérique Latine Histoire et Mémoire. Les Cahiers ALHIM [En línea], 8/2004, Publicado el 14 febrero 2005. URL: http://alhim.revues.org/414. Consultado el 02 junio 2015.

GIUNTA, Andrea. Vanguardia, internacionalismo y política: arte argentino en los años sesenta. Buenos Aires: Barcelona, México: Paidós, 2001.

HARVEY, David. A arte de lucrar: globalização, monopólio e exploração da cultura. Trad. Maria Beatriz Medina. In: MORAES, Dênis de. Por uma outra comunicação: mídia, mundialização cultural e poder. Vários tradutores. Rio de Janeiro: Record, 2003, p. 139-171.

ITDT. Le Parc. Buenos Aires: Edición Fondo Nacional de las Artes, 1967. [Catálogo]

. Premio nacional e internacional del Instituto Torcuato Di Tella 1964. Buenos Aires: Imprenta Anzilotti, 1964. [Catálogo, 74p.]

JAMESON, Fredric. Le postmodernisme ou la logique culturelle du capitalisme tardif. Trad. Florence Nevoltry. Paris: Beaux Arts Éditions, 2011.

KANTT, Nathalie. Le Parc en boca de todos. La Nación, Buenos Aires, 28 set. 2014 [En línea]. URL: http://www.lanacion.com.ar/1730320-le-parc-en-boca-de-todos. Consultado el 17 enero 2015.

KATZENSTEIN, Inés. Escritos de vanguardia. Arte argentino de los años 60. Buenos Aires: The Museum of Modern Art, Fundación Proa, Fundación espigas, 2007.

KRAMER. Antje. Les grands manifestes de l'art des XIX ${ }^{e m}$ et XX $X^{e m}$ siècle. Paris : Beaux Arts Éditions, 2011. 
LEMOINE, S. (dir.). Dynamo: un siècle de lumière et de mouvement dans l'art: 1913-2013 (dir. Serge Lemoine). Paris: Réunion des Musées Nationaux - Grand Palais (au Grand Palis, 10 avril au 22 juillet, 2013), 2013.

LE PARC. J. Historieta: petite histoire en images interrogeant la face caché de l'art, de l'artiste et de son contexte social (suivi de "La Petite Histoire de Julio Le Parc" de Jean-Louis Pradel). Nantes: Éditions Joca Seria, 1997.

La valoración: arma clave para la penetración cultural. In: Ponencias I encuentro de intelectuales por la soberanía de los pueblos de nuestra américa. La Habana: Casa de las Américas, 1985.

. Voleur de Paroles. Paris: Éditions Jannink, 2013.

LONGONI, Ana, MESTMAN, Mariano. Del Di Tella a Tucumán Arde: vanguardia artística y política en el 68' argentino. 1a ed. 3a reimp. Buenos Aires: Eudeba, 2013.

LONGONI, Ana. Vanguardia y revolución: arte e izquierdas en la Argentina de los sesenta-setenta. Buenos Aires: Ariel, 2014.

NOÉ, Luis Felipe. Noescritos sobre eso que se llama arte (1966-2006). Buenos Aires: Adriana Hidalgo Editora, 2009.

PEDROSA, Mário. Política das artes: textos escolhidos I. (org. Otília B. F. Arantes). São Paulo: EDUSP, 1995.

PLANTE, Isabel. Amérique Latine Non Officielle o París como lugar para exhibir contrainformación. $A$ Contracorriente. Vol. 10, n. 2, Winter, 2013a, p. 58-84. [En línea]. URL: http://acontracorriente.chass.ncsu.edu/index.php/acontracorriente/article/viewFile/341/1154.

Consultado el 18 marzo 2015. $2013 \mathrm{~b}$.

. Argentinos de París: arte y viajes culturales durante los años sesenta. Buenos Aires: Edhasa,

TRABA, Marta. Venezuela: como se forma uma plástica hegemônic. In: PONTUAL, Roberto (org.). América Latina: geometria sensível. Rio de Janeiro: Jornal do Brasil/GBM, 1978, p. 87-100. 